\title{
Online Disinformation and the Psychological Bases of Prejudice and Political Conservatism
}

\author{
Argha Ray \\ Iowa State University \\ argharay@iastate.edu
}

\author{
Joey F. George \\ Iowa State University \\ jfgeorge@iastate.edu
}

\begin{abstract}
It is widely believed that the impact of fake news, internet rumors, hoaxes, deceptive memes etc. are spilling into the physical world from the virtual world. In fact, social media has had a significant role in the origination and spread of such deceptive communication, as social media users often lack awareness of the intentional manipulation of online content and are easily tricked into believing unverifiable content. In an increasingly polarized world where social media and the internet have pushed people to live inside "echo chambers" and "filter bubbles," people consciously and unconsciously are exposed only to content that reinforce their confirmation bias. In such a scenario, people only agree with content that aligns with their preexisting beliefs and disagree with or label as "fake" content that is opposed to their worldview. This paper proposes to study the psychological differences that cause people to either agree or disagree with such prejudiced and ideologically oriented online disinformation.
\end{abstract}

\section{Introduction}

Disinformation, the English translation of the Russian word Dezinformatsiya, was coined by Joseph Stalin to ostensibly refer to dissemination of false reports to mislead public opinion in the Soviet Union by the West [51]. In contemporary usage, the University of Michigan Library's Research Guide describes disinformation as deliberate, while misinformation is the inadvertent creation and spread of inaccurate information. The larger ecosystem of mis-and disinformation is roughly of 7 types: satire or parody, misleading content, imposter content, fabricated content, false connection, false context and manipulated content. In this paper we focus on disinformation that is partisan, sensationalist and inflammatory in nature, and designed to sway public opinion towards political ends, deepen societal fissures, pit one group against another, foment hatred, and incite violence. Such disinformation with an intent to deceive is widespread.

In July 2016, the now defunct website wtoe5news.com spread lies that Pope Francis had endorsed Donald Trump in his bid for US presidency. Allcott and Gentzkow [16] studied the phenomenon of rampant disinformation that was circulated during the 2016 US Presidential elections but stopped short of providing an assessment on the pivotal role it played in electing one candidate over the other. Disinformation not only affects political discourse but also affects social discourse. During the same election, North Carolina resident, Edgar Maddison Welch, armed with an assault rifle, fired a shot at a Washington DC pizza joint where he had come to "self-investigate" an alleged claim that US Presidential Candidate, Hillary Clinton, with her campaign chief, John Podesta, was running a pedophilia ring out of the restaurant [49]. Disinformation is not limited to the US - it has worldwide ramifications. In Germany, during 2016, there were false reports that a 13-year-old girl named Lisa F of Russian origin was raped in Berlin by a group of refugees from the Middle East. This news caused hundreds to take to the streets in protest alongside far right and anti-Islamic groups [50]. In Myanmar, disinformation tinged with religious hatred was circulated on social media, leading to violence against the minority Rohingya Muslims by the majority Buddhist population [50]. During the run up to the European Union referendum in Britain, the Vote Leave campaign bankrolled nearly a billion targeted digital advertisements on social media, and among them was an image of a bus painted with the slogan "We send the EU $£ 350$ million a week," which was later found to be untrue [7]. In the Philippines, during the 2016 presidential campaign, a blog named Mocha Uson Blog, which previously used to provide sex related advice, propagated disinformation in support of presidential candidate Rodrigo Duterte [41]. In India, several Union Government Ministers have been compelled to delete misleading tweets and posts after being fact-checked online, and most such disinformation "appear[s] to support India's ruling Bharatiya Janata Party and its right-wing Hindu 
nationalist agenda" [52]. Similarly, disinformation has surfaced in Australia, Brazil, Italy and elsewhere. But, disinformation or propaganda is not a new phenomenon. It is almost as old as civilization itself. In 13th Century BC, emperor Rameses the Great spread falsehoods about his supposed victory in the Battle of Kadesh against the Hittites, when the battle was actually a stalemate [57]. In 1475 AD a Franciscan preacher, Bernardino da Feltre, spread a rumor in Trent, Italy, that the Jewish community murdered a two-and-a-half-year-old child named Simonino and drank his blood to celebrate Passover. This resulted in the torture of the Jewish community, with 15 people burned alive at the stake. These false "blood libel" stories were responsible, in part, in laying the foundation for anti-Semitism [35]. During World War I, the Allied press was awash with false propaganda about a supposed factory which extracted body fat from dead German soldiers to manufacture nitroglycerine, candles, soaps, lubricants etc. This story on the "German Corpse factory" was later used by Nazi Propaganda Minister Joseph Goebbels, during World War II, to deny the ongoing massacre of Jews in Nazi concentration camps and described it as British propaganda [6].

All these anecdotal accounts of online or offline disinformation have an underlying consistency: they were either ethnocentrically prejudiced or were ideologically motivated. As a matter of fact, a significant portion of disinformation and propaganda that are in circulation online are politically motivated and are propagated with the aim of political or social polarization by appealing to our inherent and primal prejudices. Such ideologically oriented and prejudiced disinformation is not only consumed but also believed. Contentiously, ideological orientation has had a very controversial history in research on prejudice. The controversy arises due to research that has consistently found correlation between prejudice and conservatism as if conservatives are the "designated villains" of prejudice. Two reasons are forwarded for this correlation between prejudice and conservatism: (a) conservatism does not cause prejudice but prejudiced individuals use conservative beliefs to justify their prejudice, and (b) compared to liberals, conservatives are more likely to see people themselves, as opposed to economic and social conditions, being responsible for negative outcomes, such as high unemployment rate among blacks being a result of laziness. This is not to say that liberals are not prejudiced. Research has linked a covert form of prejudice, aversive racial prejudice, to liberals where people avoid contact with a racial outgroup or at most try to be polite [3]. In the world of online disinformation this may have significant repercussions. Vosoughi et al. [45], in a cover story for Science, investigated Twitter rumor cascades and concluded that falsehood diffuses "farther, faster, deeper, and more broadly" than truth on social media, as humans are more likely to spread it than bots. Such disinformation on social media is shared and consumed by both poles of the ideological spectrum. But there is empirical evidence of an asymmetry in the pattern of creation and propagation of disinformation on social media. The Computational Propaganda Project at the Oxford Internet Institute found that on Twitter and Facebook, right leaning groups shared the widest range of extremist, sensationalist, conspiratorial, fake and other forms of "junk" news, compared to all other ideological groups put together in the lead up to the 2016 US presidential election [54]. The Berkman Klein Center for Internet \& Society at Harvard University reiterates that during the same election the "more insulated right-wing media ecosystem was susceptible to sustained network propaganda and disinformation" and the "hyperpartisan, unreliable sources on the left did not receive the same amplification that equivalent sites on the right did [40]." This stark asymmetry in diffusion of disinformation on social media along ideological lines and the mature social psychology literature on prejudice and conservatism encourages a closer look at this unfolding phenomenon. Hence, our research question is as follows: Do individual differences of prejudice and conservative self-placement have an effect on the perceived credibility of disinformation that diffuses on social media? Hence, we examine the psychological variables that determine why some of us are more prejudiced and ideologically conservative than others. However, disinformation diffusion in the left-wing media ecosystem is equally noxious. For instance, disinformation showing a photograph of detained immigrant children separated from their parents in orange jumpsuits at US borders shared by the left leaning Occupy Democrats group [47] also has the potential to further deepen the cracks in an already divided society. Although, this paper focuses on only one pole of the ideological spectrum, further research that focuses on the opposite pole is also necessary. Together, it may explain why we agree or disagree with certain content even though they are outright falsehoods and consciously or unconsciously allow ourselves to be deceived by such content. The paper is organized as follows. First, we briefly review the literature on online deception and its detection. We then provide the theoretical background and introduce our conceptual model. We conclude by discussing the implications.

\section{Literature Review: Deception Detection}

The boundary between traditional news and user generated content is gradually blurring [59]. Modern 
technologies, especially mobiles, allow instant posting and sharing of content, allowing people at the location of an event to become de facto news reporters. Even journalists themselves rely heavily on social media for information, and 54\% of all US news journalists collect information from microblogging sites and report their stories [5]. This means that a large proportion of information that is consumed comes from complete strangers rather than from trusted sources [5]. Social media users have a general disposition of goodwill towards social media communication and are poor judges of the truthfulness of content that they consume [31]. The content in social media is often biased, unverifiable, subjective in nature, and created and shared with the intention to either attract online traffic for revenue or spread outright lies to create false impressions or beliefs. Thus, the potential for people to deceive by using computer-mediated communication has grown immensely with disastrous results [9]. Disinformation is often political in nature to sway opinion, and the impact is amplified as more and more people are drawn to social media to receive content by sacrificing caution for convenience [53]. In the US, 62 percent of adults get their news from social media, according to a Pew research study [19]. However, there is a growing awareness among social media platforms to look for tools to filter false content and reverse the trend. For example, Facebook has taken steps to identify news articles that are false and flag false articles as "disputed by 3rd party fact-checkers" [1]. This entire phenomenon of disinformation can be dealt with using the lens of the deception detection literature. The literature is both technical and behavioral in nature. As explained below, the technical research effort has focused on automated detection of deception, whereas the behavioral research effort has focused on the development of theories that inform on the psycho-sociological antecedents and consequences of deception detection.

The literature on automated deception detection in computer mediated communication can be broadly classified into two categories viz. Linguistic Analysis and Network Analysis. There are several successful studies on deception detection that use linguistic cues to identify deceptive communication, as the language used by truth-tellers is different from that of deceivers. For instance, Zhou et al. [25] reviewed several systems for deception detection in textual communication and identified 27 linguistic features classified under 9 broad conceptual clusters that are amenable to automation for classifying texts as either deceptive or truthful. Apart from linguistic analysis, Rubin [53] notes that false content can be detected based on "positioning of the message sources in the network, their reputation, trustworthiness, credibility, expertise, as well as propensity for spreading rumors" (p.12). These techniques fall under the category of Network Analysis. Liu et al. [58] proposed a technique to automatically debunk rumors on Twitter in real time by using verification features based upon insights from journalists. However, in spite of the progress in creating algorithms to detect false content, the success rate has not been substantial, and human fact checking, as done by Politifact and Snopes, is still more credible in identifying false content, even though it is expensive to employ human beings to sift through huge amounts of data that flood the social media every moment. Thus, Rubin [53] calls for a hybrid approach to false content detection. She asserts, "When analyzing social media for potentially deceptive content, it is important to apply methods that consider not just what is being said, but also how the message is presented, by who, and in what format and context. The hybrid approach should include text analytics, network analysis and world knowledge database incorporation to fully take advantage of linguistic, interpersonal, and contextual awareness.” (p.22)

On the other hand, prominent theories and methods have been developed to analyze deceptive discourse in the behavioral stream. Such theories include ContentBased Criteria Analysis (CBCA) [2], Reality Monitoring (RM) [30], Scientific Content Analysis (SCAN) [26], Interpersonal Deception Theory (IDT) [10], Information Manipulation Theory (IMT) [46], Leakage Theory [34], Prominence-Interpretation Theory (PIT) [4] and Four Factor Theory (FFT) [32]. Despite the development of such theories on deception detection, research has not been able to pinpoint a set of reliable behavioral indicators of deception, and investigation on behavioral cues such as posture shifts, pupil dilation, gaze aversion, fidgeting, or foot and hand movements haven't led to much success. The running average for thousands of participants, who have participated in several deception detection experiments conducted over the decades, reveals that most participants are not very good at detecting deception, with documented success rates of just $54 \%$, which is slightly better than chance [8]. Under these circumstances, our paper focuses on an entirely different set of attitudinal proclivities that may affect deception detection accuracy, and the attitudinal biases hinge on people's ingrained belief systems. Though social psychological constructs may not have been explicitly investigated by deception detection researchers, Schindler et al. [44] have shown the effect of interaction between the Belief in Just World construct, drawn from the Just World Theory [29], and Mortality Salience construct, drawn from Terror Management Theory [21], on deception detection accuracy. 


\section{Theory and Propositions}

In developing our conceptual model, we draw heavily from the social and political psychology literature and the deception detection literature. We specifically base our conceptual model on the Expanded Prominence Interpretation Theory [18] and contend that individual differences and situational factors related to motivated social cognition play an important role in assessing the credibility of online disinformation.

\subsection{Research Model: Expanded Prominence Interpretation Theory (EPIT)}

George et al. [18] developed EPIT as an extension of the Prominence Interpretation Theory (PIT) of Fogg [4] by supplementing it with another theory based on the seminal work of Buller and Burgoon [10], Interpersonal Deception Theory (IDT). The original PIT theory was introduced after four years of extensive research on website credibility at Stanford's Persuasive Technology Lab. The theory posits that two things happen when people assess the credibility of websites. The user first notices something (Prominence), and then the user makes a judgment about what was noticed (Interpretation). Initially, Fogg [4] proposed that five factors affect Prominence: (a) Involvement of the user, (b) the Topic of the website, (c) the Task the user is performing, (d) Experience of the user, and (e) Individual Differences. Interpretation, on the other hand, is impacted by three factors: (a) Assumptions in the user's mind, (b) Skills or Knowledge of the user, and (c) Context in which the user operates. George et al. [18] added new factors and modified existing factors that affect Prominence and Interpretation, accounted for the temporal nature of communication, and incorporated relationships among Media, Credibility and Deception Detection. Even though both PIT and IDT are process models, George et al. [18] interpret EPIT as a causal model where Interpretation acts as a moderator on the link between Prominence and Credibility. They opine that the relationship between Prominence and Credibility holds even in the absence of a clearly articulated Interpretation, as Interpretation may be conscious or tacit. They also remark that the broad nature of EPIT can potentially deal with any type of Credibility, including Credibility of Information, as Credibility essentially acts as a mediator between the upstream construct of Media and a more general downstream construct of Judgement. Figure 1 depicts an adapted version of EPIT as proposed by George et al. [18] as a state in the communication process at one point in time.

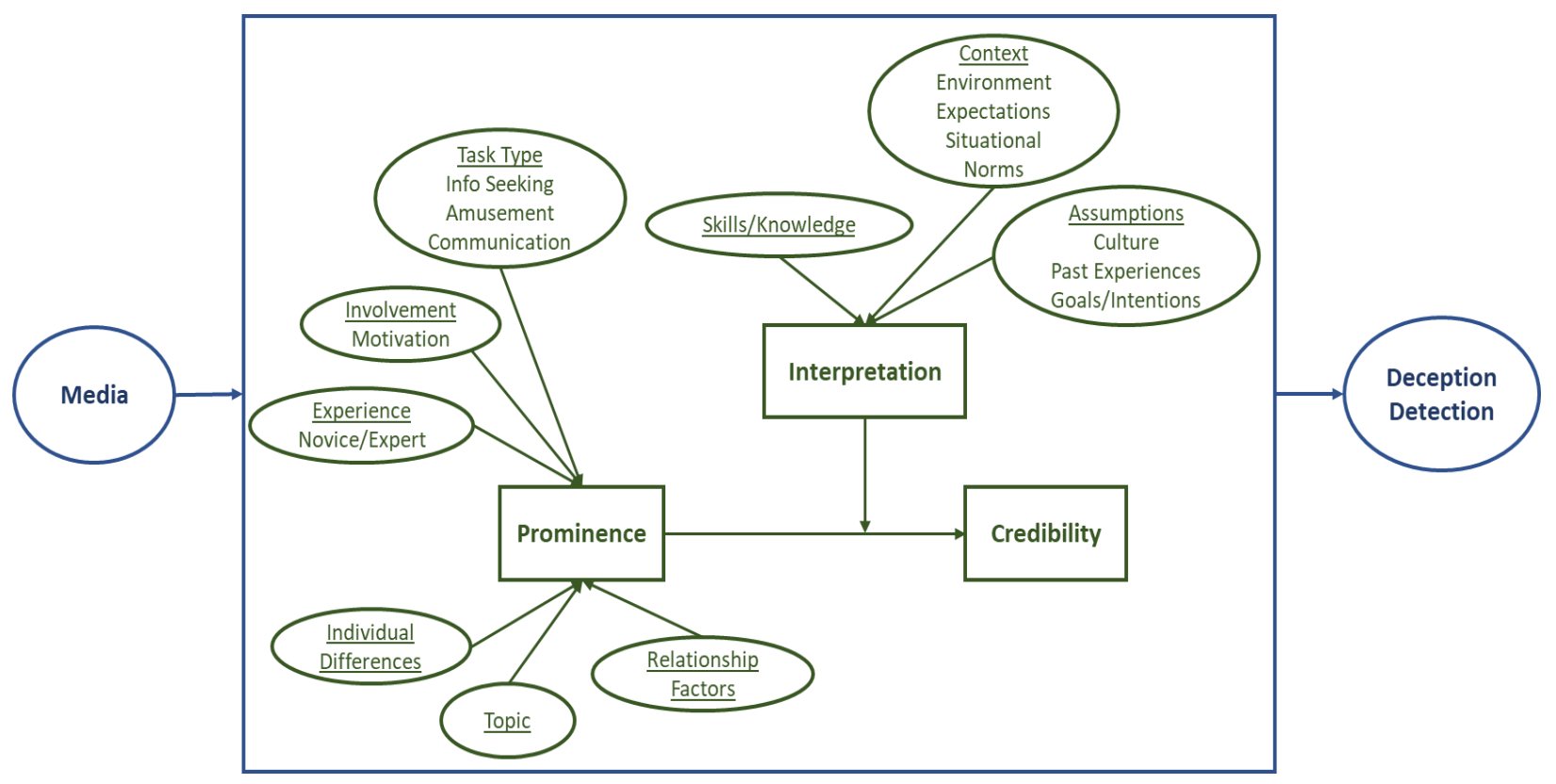

Figure 1. Expanded Prominence Interpretation Theory (EPIT) at one point in time in the communication process [18]

Since we focus primarily on whether certain individuals than others are more likely to be deceived by prejudiced online content, we restrict ourselves to only Individual Differences that are linked with prejudice and that may have a plausible effect on Prominence, as well as a situational factor that may 
influence the relationship between Individual Difference and Prominence. Additionally, George et al. [18] have indicated that the antecedents to Prominence are easy to measure and manipulate, but Interpretation is particularly difficult to identify, measure, and manipulate. Hence, our model only considers how Individual Differences bias Prominence moderated by a situational factor, and how Prominence in turn impacts Credibility assessment, while ignoring Interpretation (Figure 2). We now take recourse to the social and political psychology literature to argue that Individual Differences related to prejudice and political conservatism are a result of Motivated Social Cognition that conspicuously influence how we interpret information that transgress or bolster our cultural worldviews. Later, we also look at a situational factor that heightens prejudicial tendencies.

\subsection{Motivated Social Cognition}

Motivated Social Cognition or Motivated Reasoning allows people to believe what they want to believe, subject to certain reality constraints. Personal or social goals and motives that people have affect their reasoning, and they are likely to arrive at conclusions that they want to arrive at. Human beliefs are subjectively rational and are guided by both directional and non-directional motives based on a set of premises that the believers subscribe in [23]. Directional motives reflect the desire to reach a predetermined conclusion, while non-directional motives reflect the desire to arrive at an accurate conclusion based on deep and careful cognitive processing by reducing bias. If guided by directional motives, people undertake a more intense search of knowledge structures-- memories, beliefs, and rulesto access only hypothesis confirming information, and in process, suppress disconfirming evidence [60]. Only information that supports prior beliefs is readily assimilated, and this information plays a rationalizing and legitimizing role in the preservation of ideological belief systems. Hence, people adopt ideological belief systems such as Political Conservatism as it satisfies their prior epistemic commitments and psychological needs and motives.

\subsection{Political Conservatism and Prejudice}

The word ideology was coined by Antoine Destutt de Tracy in 1796 during the Great Terror of the French Revolution, a phase of the revolution punctuated by unrestrained mob violence. Though initially a liberal philosophy, Napoleon, after pretending to share the liberalism with ideologists of Tracy's National Institute, later referred to them pejoratively as "ideologues" when he consolidated power during the early months of the French Republic [11]. Since the time of the French Revolution, ideological opinions have been classified most often in terms of a single left-right dimension. In modern usage as well, ideology predominantly has a unidimensional connotation of a left-right divide, which has its roots from late 18th century sitting arrangement in the French Assembly Hall, where supporters of status quo were seated on the right side of the Assembly, and their opponents were seated on the left. In the United States and other parts of the world, it has been common to substitute "liberal" for "left" and "conservative" for "right" [22]. Though this unidimensional bipolar left-right model of ideological structure has been criticized in the literature, and multidimensional models of ideological structure have been proposed, the parsimonious unidimensional model has withstood the test of theoretical utility and empirical validity. Conservatism and Liberalism have consistently been shown to hold a negative relationship in numerous factor analytic studies [22]. In this paper, we adopt the unidimensional model, and we are particularly interested in the ideology of Conservatism, as it has been linked with various kinds of prejudicial dispositions both theoretically and empirically. Wilson [13] constructed the Conservatism Scale (C-Scale) and defined it as "resistance to change and the tendency to prefer safe, traditional and conventional forms of institutions and behavior" (p.4). Jost et al. [23] identify two core aspects of Conservatism. One core aspect is traditionalism and an opposition to change. The other core aspect is endorsement of inequality. These inclinations of political conservatives are generally associated with intolerance, prejudice, stereotyping, and hostility towards a wide variety of outgroups including stigmatized or disadvantaged groups. The prejudices include racism, ethnocentrism, sexism, homophobia, anti-Semitism, pseudo-patriotism, classism, disability discrimination, religious fundamentalism etc. Surprisingly, different kinds of prejudices often cluster together, and Allport [15] combined them as "generalized prejudice." He stated that "One of the facts of which we are most certain is that people who reject one out-group will tend to reject other out-groups. If a person is anti-Jewish, he is likely to be anti-Catholic, anti-Negro, anti any out-group" (p.66). Research over the years, grounded in theories of personality, documents various individual difference variables that predict the psychological basis of right wing ideology and associated prejudices. Certain situational factors also influence the expression of Conservatism and prejudices. We now illustrate the psychological and situational roots of generalized prejudice and political conservatism that we explicitly consider in our study. In terms of 
Individual Differences, Right Wing Authoritarianism and Social Dominance Orientation positively influence prejudicial propensity, while Dispositional Empathy and Polyculturalism negatively influence it. Moreover, Mortality Salience is a Situational Factor that moderates the relationship.

3.3.1. Individual Difference: Right Wing Authoritarianism. The tradition of singling out right wing rather than left wing ideology for special inquiry started with the authors of The Authoritarian Personality [48] in the backdrop of rising Fascism throughout Europe leading to World War II. Later there was a gradual loss of interest in this area due to several methodological and conceptual issues. Altemeyer [36] revived the interest by replacing Adorno and colleagues' [48] Fascism Scale (F-Scale) with his Right Wing Authoritarianism (RWA) scale. There are three distinct socio political attitudes of Right Wing Authoritarians: (a) Conventionalism defined as "a high degree of adherence to the social conventions which are perceived to be endorsed by society;" (b) Authoritarian Submission defined as "a high degree of submission to the authorities who are perceived to be established and legitimate;" (c) Authoritarian Aggression defined as "a general aggressiveness, directed against various persons, which is perceived to be sanctioned by established authorities" [36] (p.148). However, there has been criticism that authoritarianism or dogmatism is also associated with left wing extremism. Indeed, studies on Russian samples show that authoritarianism is as much a characteristic of the Communist left as is a characteristic of the Western right [37]. However, empirical evidence is unequivocally skewed in favor of the "rigidity of the right hypothesis" [33]. Altemeyer [38] exclaims "authoritarian on the left has been as scarce as hens' teeth in my samples" (p.71). In our western context we espouse this point of view. Notwithstanding the criticism, RWA has shown remarkable predictive power for generalized prejudice and political conservatism. Since persons high in RWA are generally prejudiced, discriminatory towards outgroups, and are inclined towards Conservative political orientation, we posit that they will be more likely to agree with prejudiced and ideologically aligned informational content irrespective of whether it is accurate or inaccurate. Hence, we put forward our first proposition.

Proposition 1: Persons who are high in RWA will find prejudiced content to be more credible, depending on its Prominence in social media.

3.3.2. Individual Difference: Social Dominance Orientation. Social Dominance Theory [12] postulates that societal and evolutionary factors determine the development of ideologically conservative self-placements. The theory suggests that human societies develop hierarchy-enhancing belief systems that justify hegemony of the dominant group over marginalized groups in order to minimize group conflict. This is realized by promulgating various "legitimizing myths," such as (a) "paternalistic myths," which maintain that dominant groups are indispensable to protect and lead subordinate groups who are incapable of doing so by themselves; (b) "sacred myths," which claim that positions of supremacy are a divine right determined by the Almighty; (c) "reciprocal myths," which proclaim that there is a preordained symbiotic exchange between the dominant and subordinate group that benefit each other. These ideological devices allow the primacy of one group over others in terms of economic status, race, ethnicity, gender, etc., and hinder social change in terms of equitable distribution of power, wealth, or social status. While high RWAs "fear that authority and conventions are crumbling so quickly that civilization will collapse, and they will be eaten in the resulting jungle," people who score high on the Social Dominance Orientation (SDO) scale "already see life as 'dog eat dog' and-compared with most people -- are determined to do the eating" [38] (p.75) by becoming "the alpha animal" [38] (p.87). Duckitt and Sibley [17] reflect that "RWA should be more predictive of the conservative, religious, traditional, clerical brand of fascism characterized by Franco's Spain, whereas SDO should be more predictive of the aggressive, dominative, militaristic fascism that was characterized by Hitler's Nazi party" (p.1878). Over the years, RWA and SDO have together predicted an average of 50\% of statistical variance in generalized prejudice, and Altemeyer [38] called them the "Lethal Union." Like RWAs, high SDOs are generally prejudiced, discriminatory towards outgroups, and are inclined towards Conservative political orientation. Hence, we deduce that they will be more likely to agree with prejudiced and ideologically aligned informational content irrespective of whether it is accurate or inaccurate. Thus, our second proposition follows.

Proposition 2: Persons who are high in SDO will find prejudiced content to be more credible, depending on its Prominence in social media.

3.3.3. Individual Difference: Dispositional Empathy. While studying other roots of generalized prejudice, apart from RWA and SDO, McFarland and Adelson [42] in an omnibus study reported gender to be a significant determinant. Being male makes one more prejudiced than being female. Individual differences in gender reveal that females have higher dispositional Empathy, while males have higher 
narcissism and masculinity. McFarland [43] studied these factors and detailed that dispositional Empathy was the third most important factor that predicted generalized prejudice along with RWA and SDO, and he termed them as the "Big Three." Two primary facets of empathy have shown to be antithetical to prejudice: (a) "Empathic Concern," which is a feeling of sympathy and compassion for unfortunate others; (b) "Perspective Taking," which is a tendency to spontaneously adopt the perspective or psychological point of view of others [28]. Bäckström and Björklund [27] used a structural model and found that differences in Empathy, measured using subscales from Davis' [28] Interpersonal Reactivity Index, primarily explained individual differences in prejudice stemming from sex differences. Compassion for others doubtlessly makes one more likely to sympathize with underprivileged outgroups and to appreciate their concerns. Therefore, we extend our third proposition.

Proposition 3: Persons who are high in Empathy will find prejudiced content to be less credible, depending on its Prominence in social media.

3.3.4. Individual Difference: Polyculturalism. A recent study by Rosenthal and Levy [24] investigated the intergroup ideology of Polyculturalism and communicated that Polyculturalism explained unique variance in prejudice over and above RWA and SDO. Polyculturalism was first proposed by historians Kelley [39] and Prashad [55,56], and it holds implications for racial and ethnic relations. People who endorse Polyculturalism focus on how cultures interact, influence and share ideas with each other and have done so throughout history. They do not view culture as static, unchanging entities that belong to a particular group but instead as deeply connected and shaped by mutual interactions among people. This is different from the concepts of Multiculturalism and Colorblindness. While Colorblindness de-emphasizes group categories such as race, ethnicity, etc., and focus on similarities among groups, Multiculturalism emphasizes the distinctness of racial/ethnic groups and focuses on understanding each other's rich histories and customs. Though Polyculturalism, like Multiculturalism, recognizes racial and ethnic differences, its principal focus is on the "interconnections" among groups, unlike the focus on cross-group similarities in Colorblindness. As Kelley [39] puts it "All of us, and I mean ALL of us, are the inheritors of European, African, Native American, and even Asian pasts, even if we can't exactly trace our blood lines to all of these continents" (p. 81). Since, Polyculturalism fosters positive intergroup contact, greater interest in diversity, and greater appreciation for differences, it has been shown to reduce prejudice such as sexism and discrimination towards the Lesbian, Gay, Bisexual, Transgender, Intersex (LGBTI) community. This leads to our fourth proposition.

Proposition 4: Persons who are high in Polyculturalism will find prejudiced content to be less credible, depending on its Prominence in social media.

3.3.5. Situational Factor: Mortality Salience. Now that we have looked at the Individual Differences in the above sections, we turn our attention to a situational factor that may influence the relationships between Individual Differences and Prominence. Allport [15] in his classical essay expressed that prejudice is not rooted just in personality differences. It is also influenced by a group's specific history, sociocultural setting, and situational factors. The situational factor we canvas is Mortality Salience, which has a long history in research related to prejudice. According to Terror Management Theory [21], fear of death is rooted in the basic human instinct of self-preservation. This instinctive drive and an awareness of the inevitability of death creates paralyzing terror. Culture and concomitant worldviews act as an anxiety buffer by which human beings cope with this existential threat arising out of the thoughts of one's own mortality. To the extent that this cultural worldview buffer allows human beings to symbolically transcend death, the reminder of death elicits strong negative response to events that violate the cultural worldview and positive response to events that uphold the worldview. Hence, salience of one's own mortality engenders defense and justification of cultural worldviews and systems of meaning such as religion and intolerance for alternative social or political worldviews. Over time, research has established that conservative thoughts and behaviors are amplified under a heightened sense of terror leading to more prejudice. Consequently, we submit our fifth proposition.

Proposition 5: Mortality Salience interacts with, and hence moderates the relationship between Individual Differences and the Prominence of social media content.

Our conceptual model is in Figure 2. In the model, Right Wing Authoritarianism, Social Dominance Orientation, Dispositional Empathy, and Endorsement of Polyculturalism are the Individual Differences which affect Prominence. Prominence mediates the relationship between Individual Differences and Credibility assessment. Mortality Salience moderates the relationship between Individual Differences and Prominence. 


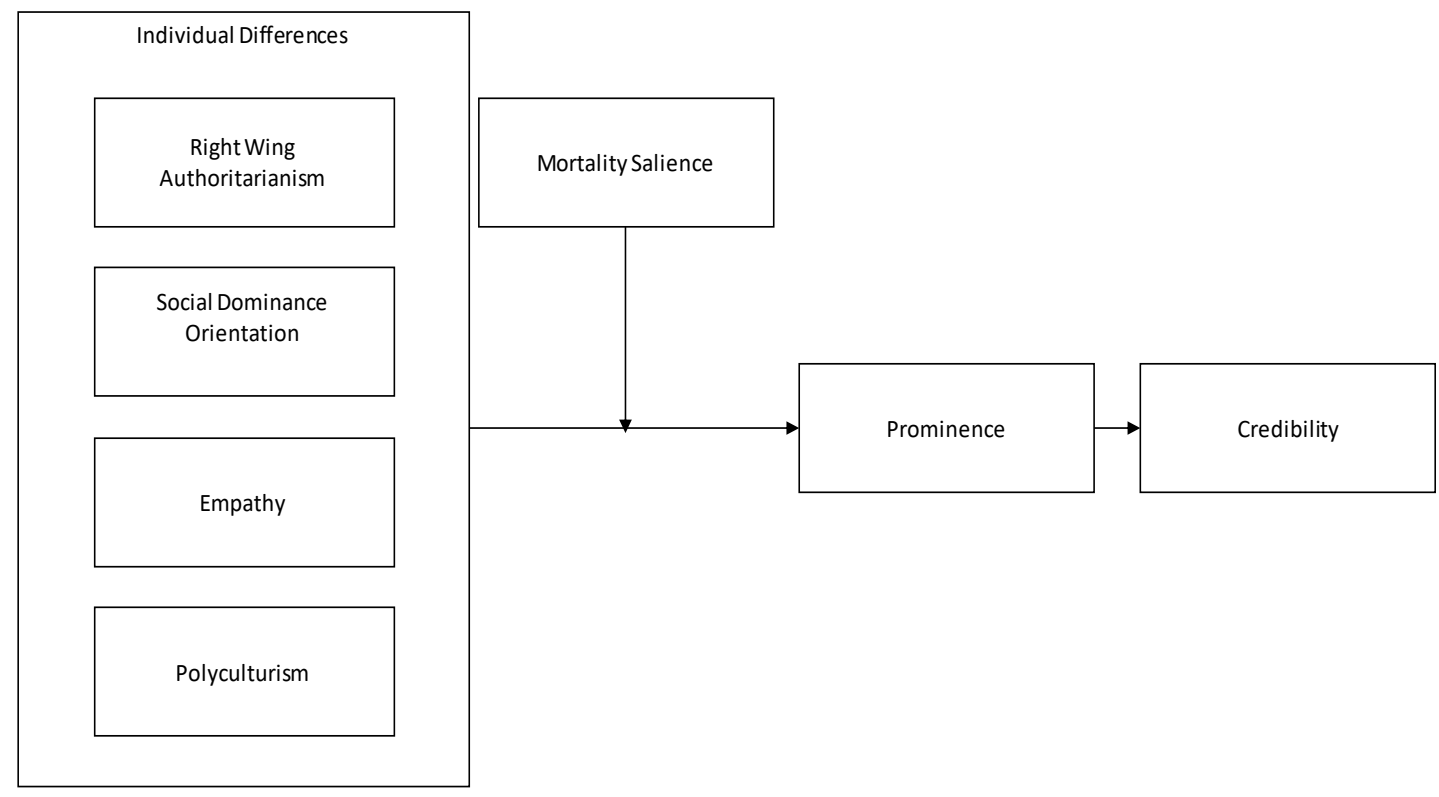

Figure 2. Conceptual Model

\section{Implications}

We have proposed a novel framework to study online disinformation by marrying the literatures from Deception Detection and Social and Political Psychology. EPIT provides the foundation on which we build our model, and we reckon that individual differences may hold the key to understanding why online disinformation spreads, and what makes people so susceptible. As such, we broaden EPIT itself and apply it in the specific context of prejudicially motivated online deception. If our propositions are empirically established, it may unlock new avenues about how online disinformation is countered, and on the downside it may provide ammunition to offenders about how and whom to target with their malicious content. We also introduce several scales from the Social and Political Psychology literature which have hitherto not been used in the Information Systems discipline. As for other research in this area, Pennycook and Rand [14] have investigated the role of analytic thinking in the detection of "fake news," and they have shown that right leaning individuals who supported one US Presidential candidate over the other engaged in less analytical thinking and were less able to detect fake from real news, compared to left leaning individuals who supported the rival. But ours is a larger perspective. We do not restrict ourselves to political party or candidate affiliations but deal with broader conceptions of prejudice and conservatism. But, this is only half of the story. Here we ignore the linkage between prejudice and liberalism, and the disinformation campaigns that also plague the left leaning media ecosystem. This calls for further research that restores parity. As Greenberg and Jonas [20], in their rejoinder to Jost et al. [23], had aptly reminded, "psychological theorizing and research on political attitudes always run the risk of being guided by the motivated social cognition of the theorists and researchers on the basis of their own sociopolitical views," and there should be a "counterweight toward balance and diversity in the application of motivated social cognition to understanding the determinants of political orientation."

\section{References}

[1] A. Mosseri, "News Feed FYI Addressing Hoaxes and Fake News." Newsroom, Facebook, December 15. http://newsroom.fb.com/news/2016/12/newsfeed-fyi- ddressinghoaxes-and-fake-news/, 2016.

[2] A. Vrij, Criteria-Based Content Analysis: A Qualitative Review of the First 37 Studies, Psychology, Public Policy, and Law, 11, 2005, pp. 3-41.

[3] E. Whitley Jr., and M.E. Kite, The psychology of prejudice and discrimination (2e). Belmont, CA: Thomson-Wadsworth, 2010.

[4] B. J. Fogg, Prominence-interpretation theory: Explaining how people assess credibility online. CHI 2003, Ft. Lauderdale, FL, 2003, pp. 722-723. 
[5] B. Kang, T. Höllerer, and J. O'donovan, Believe it or Not? Analyzing Information Credibility in Microblogs. Proceedings of the 2015 IEEE/ACM International Conference on Advances in Social Networks Analysis and Mining 2015, ACM, 2015, pp. 611-616.

[6] BBC, "The corpse factory and the birth of fake news",

http://www.bbc.co.uk/news/entertainment-arts38995205, 2017b.

[7] BBC, Lies, Propaganda and fake news: A challenge for our age, http://www.bbc.com/future/story/20170301-liespropaganda-and-fake-news-a-grand-challenge-ofour-age, 2017a.

[8] C. F. Bond, and B. M. DePaulo, Accuracy of deception judgments. Personality and Social Psychology Review, 10(3), 2006, pp. 214-234.

[9] C. M. Fuller, D. P. Biros, and R. L. Wilson, Decision support for determining veracity via linguistic-based cues. Decision Support Systems, 46, 2009, pp. 695-703.

[10] D.B. Buller, and J. K. Burgoon, Interpersonal Deception Theory Communication Theory, 6, 1996, pp. 203-242.

[11] E. Kennedy, "Ideology" from Destutt De Tracy to Marx". Journal of the History of Ideas. 40 (3), 1979 , pp. 353-368.

[12] F. Pratto, J. Sidanius, L. M. Stallworth, and B. F. Malle, Social dominance orientation: A personality variable predicting social and political attitudes. Journal of Personality and Social Psychology, 67, 1994, pp. 741-763.

[13] G. D. Wilson, The psychology of conservatism. London: Academic Press, 1973c.

[14] G. Pennycook, and D. G. Rand, Who Falls for Fake News? The Roles of Analytic Thinking, Motivated Reasoning, Political Ideology, and Bullshit Receptivity (September 12, 2017). Unpublished Manuscript. Available at SSRN: https://ssrn.com/abstract=3023545 or http ://dx.doi.org/10.2139/ssrn.3023545, 2017.

[15] G. W. Allport, The nature of prejudice. Garden City, NY: Addison-Wesley, 1954.

[16] Allcott, and M. Gentzkow, Social Media and Fake News in the 2016 Election. Journal of Economic Perspectives_-Volume 31, Number 2 Spring 2017, pp. 211-236.

[17] J. Duckitt, and C. G. Sibley, Personality, Ideology, Prejudice, and Politics: A Dual-Process
Motivational Model, Journal of Personality 78:6, December, 2010.

[18] J. F. George, G., Giordano, and P. A. Tilley, Website credibility and deceiver credibility: Expanding Prominence-Interpretation Theory, Computers in Human Behavior 54. 2016, pp. 8393.

[19] J. Gottfried, and E.Shearer, "News Use across Social Media Platforms 2016." Pew Research Center, May 26. http://www.journalism.org/2016/05/26/news-useacrosssocial-media-platforms-2016, 2016.

[20] J. Greenberg, and E. Jonas, Psychological Motives and Political Orientation-The Left, the Right, and the Rigid: Comment on Jost et al. (2003), Psychological Bulletin, Vol. 129, No. 3, 2003, pp. 376-382.

[21] J. Greenberg, T. Pyszczynski, and S. Solomon, The causes and consequences of the need for selfesteem: A terror management theory. In R. F. Baumeister (Ed.), Public self and private self, New York: Springer-Verlag, 1986, pp. 189-207.

[22] J. T. Jost, C. M. Federico, and J. L. Napier, Political Ideology: Its Structure, Functions, and Elective Affinities, Annual Review of Psychology.60, 2009. pp. 307-37.

[23] J. T. Jost, J. Glaser, A.W. Kruglanski, and F. J. Sulloway, Political Conservatism as Motivated Social Cognition, Psychological Bulletin, Vol. 129, No. 3, 2003, pp. 339-375.

[24] L. Rosenthal and S. R. Levy, The Relation Between Polyculturalism and Intergroup Attitudes Among Racially and Ethnically Diverse Adults, Cultural Diversity and Ethnic Minority Psychology, Vol. 18, No. 1, 2012, pp. 1-16.

[25] L. Zhou, J. K. Burgoon, J. F. Nunamaker, and D. Twitchell, Automating Linguistics-Based Cues for Detecting Deception in Text-Based Asynchronous Computer-Mediated Communications. Group Decision and Negotiation, 13, 2004, pp. 81-106.

[26] L.N. Driscoll, A Validity Assessment of Written Statements from Suspects in Criminal Investigations Using the Scan Technique, Police Studies: The International Review of Police Development, 17, 4, 1994, pp. 77-88.

M. Bäckström, and F. Björklund, Structural Modeling of Generalized Prejudice: The Role of Social Dominance, Authoritarianism, and Empathy, Journal of Individual Differences, Vol. 28(1), 2007, pp. 10-17. 
[28] M. H. Davis, Measuring individual differences in empathy: Evidence for a multidimensional approach. Journal of Personality and Social Psychology, 44, 1983, pp. 113-126.

[29] M. J. Lerner, The belief in a just world: A fundamental delusion. New York: Plenum Press, 1980.

[30] M. Johnson, and C. Raye, Reality Monitoring, Psychological Review, 88, 1981, pp. 67-85.

[31] M. R. Morris, S. Counts, A. Roseway, A. Hoff, and J. Schwarz, Tweeting is believing? understanding microblog credibility perceptions. Proceedings of the ACM 2012 conference on Computer Supported Cooperative Work, ACM, 2012, pp. 441-450.

[32] M. Zuckerman, B.M. DePaulo, and R. Rosenthal, Verbal and Nonverbal Communication of Deception, Advances In Experimental Social Psychology. New York, NY: Academic Press, 1981.

[33] P. E. Tetlock, K. A. Hannum, and P. M. Micheletti, Stability and change in the complexity of senatorial debate: Testing the cognitive versus rhetorical style hypotheses. Journal of Personality and Social Psychology, 46, 1984, pp. 979-990.

[34] P. Ekman, \& W.V. Friesen, Nonverbal Leakage and Clues to Deception, Psychiatry 32, 1969, pp. 88-106.

[35] Politico, The Long and Brutal History of Fake News.

http://www.politico.com/magazine/story/2016/12

/fake-news-history-long-violent-214535, 2016.

[36] R. A. Altemeyer, Right-wing authoritarianism. Winnipeg, Manitoba, Canada: University of Manitoba Press, 1981.

[37] R. A. Altemeyer, The authoritarian specter. Cambridge, MA: Harvard University Press, 1996.

[38] R. A. Altemeyer, The other "authoritarian personality." In M. P. Zanna (Ed.), Advances in experimental social psychology Vol. 30, New York: Academic Press, 1998, pp. 47-91.

[39] R. D. G. Kelley, The people in me. Utne Reader, 95, 1999, pp. 79-81.

[40] R. M. Faris, H. Roberts, B. Etling, N. Bourassa, E. Zuckerman, and Y. Benkler, Partisanship, Propaganda, and Disinformation: Online Media and the 2016 U.S. Presidential Election. Berkman Klein Center for Internet \& Society Research Paper, 2017.
[41] Rappler. 'Fake news queen': Netizens slam Mocha Uson for playing victim, https://www.rappler.com/move-ph/184257-fakenews-queen-netizens-slam-mocha-uson-playingvictim, 2017.

[42] S. McFarland, and S. Adelson, An omnibus study of personality and prejudice. Paper presented at the meeting of the International Society of Political Psychology, Vancouver, Canada, 1996.

[43] S. McFarland, Authoritarianism, Social Dominance, and Other Roots of Generalized Prejudice Political Psychology, Vol. 31, No. 3 June, 2010, pp. 453-477.

[44] S. Schindler, \& M. A. Reinhard, Catching the liar as a matter of justice: Effects of belief in a just world on deception detection accuracy and the moderating role of mortality salience, Personality and Individual Differences 73, 2015, pp. 105-109.

[45] S. Vosoughi, D. Roy, \& S. Aral, The spread of true and false news online, Science, Vol. 359, Issue 6380, 2018, pp. 1146-1151.

[46] S.A. McCornack, Information Manipulation Theory, Communication Monographs, 59, 1992, pp. 1-16.

[47] Snopes.com, Are These Immigrant Children in Orange Jumpsuits? https://www.snopes.com/factcheck/are-children-orange-jumpsuits/, 2018.

[48] T. W. Adorno, E. Frenkel-Brunswik, D. J. Levinson, \& R. N. Sanford, The authoritarian personality. New York: Harper, 1950.

[49] The Atlantic, 'Pizzagate' Shooter to Serve Four Years in Jail. https://www.theatlantic.com/news/archive/2017/0 6/dcs-pizzagate-shooter-sentenced-to-4-years-injail/531381/, 2017.

[50] The Guardian, Fake news: an insidious trend that's fast becoming a global problem. https://www.theguardian.com/media/2016/dec/02 /fake-news-facebook-us-election-around-theworld, 2016.

[51] The Washington Post, Before 'fake news,' there was Soviet 'disinformation', https://www.washingtonpost.com/news/worldvie ws/wp/2016/11/26/before-fake-news-there-wassoviet-

disinformation/?noredirect $=$ on\&utm_term $=.4 \mathrm{dab}$ 29d5ce03, 2016b.

[52] The Washington Post, India's millions of new Internet users are falling for fake news sometimes with deadly consequences, https://www.washingtonpost.com/world/asia_pac ific/indias-millions-of-new-internet-users-are- 
falling-for-fake-news--sometimes-with-deadlyconsequences/2017/10/01/f078eaee-9f7f-11e78 ed4-

a750b67c552b_story.html?utm_term $=.0731 \mathrm{~b} 617$ 6313, 2016a.

[53] V. L. Rubin, Deception Detection and Rumor Debunking for Social Media. In Sloan, L. \& QuanHaase, A. (Eds.) (2017) The SAGE Handbook of Social Media Research Methods, London: SAGE. https://uk.sagepub.com/en-gb/eur/the-sagehandbook-ofsocial-media-researchmethods/book245370, 2017.

[54] Narayanan, V. Barash, J. Kelly, B. Kollanyi, L. M. Neudert, and P. N. Howard, Polarization, Partisanship and Junk News Consumption over Social Media in the US. Data Memo 2018.1. Oxford, UK: Project on Computational Propaganda, 2018.

[55] V. Prashad, Bruce Lee and the anti-imperialism of Kung Fu: A polycultural adventure. Positions, 11, 2003, pp. 51-89.

[56] V. Prashad, Everybody was Kung Fu fighting: Afro-Asian connections and the myth of cultural purity. Boston, MA: Beacon Press, 2001.

[57] W. Weir, History's Greatest Lies. Beverly, Massachusetts: Fair Winds Press. ISBN 978-159233-336-3, 2009, pp. 28-41.

[58] X. Liu, A. Nourbakhsh, Q. Li, R. Fang, and S. Shah, Real-time Rumor Debunking on Twitter. Proceedings of the 24th ACM International on Conference on Information and Knowledge Management, Melbourne, Australia. ACM, 2015, pp. 1867-1870.

[59] Y. Chen, N. J. Conroy, and V. L. Rubin, News in an online world: the need for an automatic crap detector. Proceedings of the 78th ASIS\&T Annual Meeting: Information Science with Impact: Research in and for the Community, American Society for Information Science, 81, 2015.

[60] Z. Kunda, The case for motivated reasoning. Psychological Bulletin, 108, 1990, pp. 480-498. 